\title{
Research on Financial Lever Efficiency and Risk of China Listed Companies
}

\author{
Xiangfei ZHANG \\ School of Economics \& Management \\ Beihang University \\ Beijing, China \\ e-mail: buaazhangxiangfei@qq.com
}

\author{
Manying BAI \\ School of Economics \& Management \\ Beihang University \\ Beijing, China \\ e-mail: Baimy@buaa.edu.cn
}

\begin{abstract}
This paper first reviewed the literature, focusing on the theory of capital structure and financial leverage associated theory. Analysis of the company's financial leverage to influence the company's operating performance, focusing on the situation in 2014 were done, and the enterprises in accordance with the classification of different sizes were analyzed. Also, we summarize some conclusions and recommendations on China's enterprises' using of financial leverage.
\end{abstract}

Keywords-financial leverage; 2014; financial risk; new normal economic

\section{INTRODUCTION}

\section{A. Background}

In today's society, the trend of economic globalization is very rapid, the market economy has gradually enjoys popular support. In this case, China's economic market-oriented road is irresistible, with the emergence of China's enterprises will face a very fierce competition, so, debt management has become one of the essential elements of the enterprise. If companies want to get more development opportunities, they have to choose the diversification of financing channels. In many financing channels to choose from, many of our listed companies will generally choose debt financing way to raise funds because the leverage of debt financing is relatively unique, choose debt financing has many advantages.

In view of the theory and empirical study of financial leverage, some scholars in the West have studied from different perspectives, theoretical research is mature, and many have been applied in practice. In contrast, the research of Chinese scholars has not yet formed a relatively complete theory that can guide the practice of Chinese enterprises. It can be said that the relevant research of Chinese scholars is still in the initial stage, and the relevant research in China can not grasp the characteristics of Chinese enterprises research. Not only that, China's enterprises, including listed companies, the use of financial leverage is also a problem. A question come out: How should we use financial leverage to improve the company's economic efficiency, and how should we use this "double-edged sword"? Our research will be very practical.

It is worth mentioning that in 2014, the Chinese government will fight a strong anti-corruption effect is also very significant, then the anti-corruption for listed companies have no impact on financial leverage? What is the strongest impact on which industries? In addition, China's entry into the "new normal economic", no longer take GDP as the most important thing, will this have a big impact on listed companies of the financial leverage and operating performance? These questions are worth thinking, but there is still little research on the literature, so this article intends to study 2014 as a special year also has a strong practical significance.

\section{B. Literature Review}

In the essay, "Corporate Capital Structure and Management Incentives," Johnson and Hart (1982) argue that a bankruptcy mechanism can be bound by a certain way to the management of an enterprise, and that business managers are not allowed to bankrupt, the managers have to work hard, and this formed incentive management.

Kem and Vaughan (1985) in his paper "on the leverage of the average information for the company's empirical research", they found that: the company's common stock value to some extent with the financial leverage is positively related.

In his paper, Berthard (1988) found that there is a positive correlation between the company's financial leverage and its average rate of return.

Li Xinyu (2000) pointed out in his paper "Financial Leverage Effects" that financial leverage can have a positive effect on firms under certain conditions, which is that the EBIT ratio is higher than that of debt financing.

Liu Tao (2000) in his paper "on modern corporate financial leverage" that: corporate financial leverage can play a role is based on a certain basis: whether the enterprise's investment income is higher than the impact of debt on corporate financial leverage is very big.

Zhou Pingying (2003) in his paper "moderate liability to play a financial leverage" in the study of the following points: China's enterprises' development are very different. Besides, the different regions of China and different types of enterprises also have different characteristics of debt situation.

Weide Hong and $\mathrm{Wu} \mathrm{Na}$ (2005) through their research found that: the company's financial leverage and earnings per share, and the weighted average net assets and other related performance indicators showed a significant negative correlation. 


\section{RESEARCH MethodS}

This paper assumes that the prerequisite is:

- Assuming that the impact of capital structure and value of the factors in addition to financial leverage is changing, other factors remain unchanged;

- Assuming that the role of composite leverage is not taken into account, in this study the financial and operating leverage is independent;

- Assuming that we collected the financial data of listed companies is true and effective.

This paper focuses on:

(1) The article uses SPSS and other statistical analysis software, focusing on A-share listed companies in the overall financial leverage and the role of the overall distribution of the situation, and will use the histogram to carry out some intuitive description.

(2) It is proposed to use the related software of EVIWS, MATLAB and other relevant software to analyze the relevant financial data of 2012,2013 and 2014 of listed companies in China, and analyze the impact of financial leverage of listed companies on the performance of the company. including:

Focusing on the impact of financial leverage on operational performance, the regression equation used following variables: ROA, INT, GDP, AGE, SIZE, EBIT, LEV and so on.

$$
\begin{gathered}
\mathrm{ROA}=\mathrm{C}+{ }^{\alpha}{ }_{\mathrm{AGE}+}{ }^{\beta} \mathrm{LEV}+{ }_{\mathrm{SIZE}+}{ }^{\delta} \mathrm{EBIT}{ }^{\varepsilon} \\
\mathrm{ROA}=\mathrm{C}+{ }^{\alpha}{ }_{\mathrm{AGE}+}{ }^{\beta}{ }_{\mathrm{LEV}+}{ }{ }_{\text {lgSIZE }+}{ }^{\delta}{ }_{\text {lgEBIT }+}{ }^{\varepsilon}
\end{gathered}
$$

Focusing on the impact of changes in financial leverage on the performance of the company's operations, the proposed regression equation includes the following variables: ROA, INT, GDP, AGE, SIZE, EBIT, LEV, $\Delta$ LEV, etc.

$$
\mathrm{ROA}=\mathrm{C}+{ }^{\alpha} \mathrm{AGE}+{ }_{\mathrm{LEV}+} \gamma_{\mathrm{lgSIZE}+}{ }^{\delta_{\mathrm{lgEBIT}+}}{ }^{\delta} \mathrm{dlev}+^{\varepsilon}
$$

Focusing on the impact of the company's operating performance on financial leverage changes, the proposed regression equation includes the following variables: $\Delta \mathrm{LEV}$, ROA, INT, GDP, AGE, SIZE, EBIT, LEV and so on.

$$
\mathrm{LEV}=\mathrm{C}+{ }^{\alpha}{ }_{\mathrm{AGE}+}{ }^{\beta} \text { RATE }+\gamma_{\text {lgSIZE }+}{ }^{\delta}{ }_{\text {lgEBIT }+}{ }^{\varepsilon}
$$

We add the dummy variable 2014, after 2014 we take 1, before that 0 . This is taking into account China's economic market and financial markets in 2014 changes, such as the new normal economic, anti-corruption and so on.

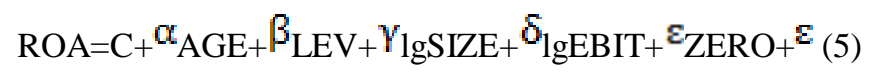

We divided the company into two different sub-samples according to certain criteria (based on a total market capitalization of 10 billion yuan): more than 10 billion for large-scale enterprises, less than 10 billion yuan for small and medium-sized enterprises. For the new samples, the regression analysis was carried out according to the models in (1) and (2).

\section{EMPIRICAL RESEARCH}

\section{A. Sample Selection and Indicators Analysis}

The empirical part of this paper chooses the data of some listed companies in Shanghai and Shenzhen in 2012, 2013 and 2014, and the financial data of each part are from the website of the forecasting person, the website of Wande and the website of the CSRC.

In the course of the study, we also processed the data with following standards:

- Excluding financial, insurance companies sample;

- Excluding the ST company's sample data;

- For those who also issued B shares and $\mathrm{H}$ shares of the company are removed;

- For the company data missing and abnormal samples are removed.

The data is processed according to the type of data required for the evidence. The finalized data types include: profit rate (expressed in terms of rate); company ages (expressed in age); company size (expressed in size and lgsize); corporate EBIT (expressed in ebit and lgebit); corporate financial leverage (expressed with lev ); the company's financial leverage changes (with dlev); and dummy variable zero. (In 2014 and later years dummy variable 1 , saying that the country's anti-corruption efforts increased significantly; other years to take 0 , saying that the anti-corruption efforts did not significantly increase ).

For the question we started at the beginning of the article, different financial scales under the size of the enterprise will not be the same? We have a classification of the total market value of the enterprises in the sample, the total market value of more than 10 billion yuan of enterprises divided into large-scale enterprises, the total value of 10 billion yuan of enterprises divided into small and medium-sized enterprises. And then on the different circumstances of the analysis.

Indicators:

1. Financial leverage $(\mathrm{LEV})=$ Total liabilities $/$ total assets * $100 \%$

2. $\mathrm{DFL}=\mathrm{EBIT} /(\mathrm{EBIT}-\mathrm{I})$

3. Return on net assets $=$ (net profit $/$ average net assets) $* 100 \%$

4. The business life of the company. According to the results of previous research, the company's operating years for the operation of the enterprise performance will have a more significant impact. In the paper, we combined with the previous research and the actual situation in China, selecting the company's operating years as an indicator to explain the company's operating performance, with age to represent. 
5. Size. As we put forward the question at the beginning of the article, will the different financial scales under the enterprise scale be different? We have a classification of the total market value of the enterprises in the sample, the total market value of more than 10 billion yuan of enterprises divided into large-scale enterprises, the total value of 10 billion yuan of enterprises divided into small and mediumsized enterprises.

\section{B. Intuitive Analysis}

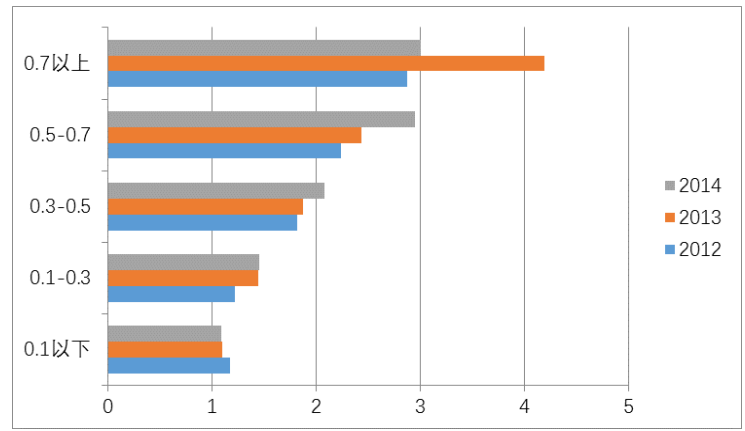

Figure 1. Changes in the proportion of financial leverage.

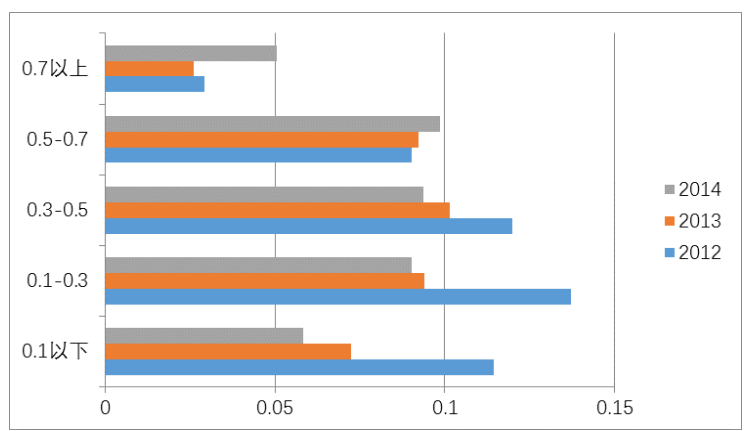

Figure 2. The change in the proportion of EBIT margin.

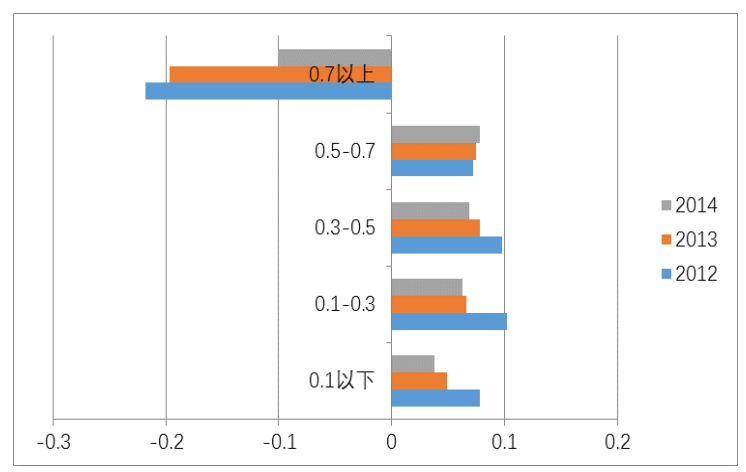

Figure 3. The proportion of return on net assets.

For the low leverage companies, there is a gradual process of leverage, but it is gradually decreasing from the rate of return and profitability. This shows that the financial leverage efficiency of listed companies in our country is lower.
For the high leverage companies, the return on net assets is negative, indicating that the leverage rate is too high for the operation of the business performance but from the surface is negative; but from 2012 to 2014, There is a gradual improvement process.

\section{Regression Analysis}

For the impact of financial leverage on operating performance, firstly we use model (1) to regress, finding that the results are not significant. After taking into account the SIZE, EBIT order of magnitude is too large, we take logarithm for SIZE and EBIT, then use model (2) to regress, and we get the result as followed:

$\mathrm{ROA}=1.18033-0.001349 \mathrm{AGE}$

0.44719LEV+0.03291lgSIZE+0.06479lgEBIT (2012)

In 2012, the impact of financial leverage on the performance of the company's operations was negative, which means that in that case, the company's higher financial leverage, the company's operating performance will be poor.

ROA $=1.48023-0.00000107 \mathrm{AGE}-$ $0.440121 \mathrm{LEV}+0.065856 \operatorname{lgSIZE}+0.020497 \operatorname{lgEBIT}$ (2013)

In 2013, the impact of financial leverage on the performance of the company is also negative, which means that in this case, the company's higher financial leverage, the company's operating performance will be poor.

$\mathrm{ROA}=-2.324-$ $0.0019 \mathrm{AGE}+0.0354 \mathrm{LEV}+0.277 \mathrm{gSIZE}+0.175 \operatorname{lgEBIT}$ (2014)

In 2014, the impact of financial leverage on the performance of the company is positive, which means that in this case, the company's financial leverage is higher, the company's operating performance will be better.

In contrast to the results of 2012, 2013 and 2014, we found that financial leverage for 2012 and 2013 was negative for the company's operating performance, while in 2014 the opposite was true. Why does this happen? We added the dlev variable (the change in financial leverage) to re-analyze the 2014 company data. (model 3 )

$\mathrm{ROA}=-2.40282-0.00321 \mathrm{AGE}-$

$0.1247 \mathrm{LEV}+0.12738 \mathrm{gSIZE}+0.01169 \mathrm{gEBIT}+1.0432 \mathrm{DLEV}$

We found that lev coefficient is negative, while dlev coefficient is positive, which means that with the increase in financial leverage, the company's operating performance will be relatively poor; the greater the reduction in financial leverage, the company's operating performance will be better.

For the impact of corporate performance on financial leverage, firstly we use model (4) to do the regression, and we get the results:

LEV $=1.733686-0.000582$ AGE-0.428696RATE$0.083622 \operatorname{lgSIZE}+0.039023 \operatorname{lgEBIT}$ (2012)

In 2012, with the company's operating conditions improved, the company is more inclined to narrow the financial leverage.

LEV $=1.850246+0.001368$ AGE-0.49794RATE$0.09141 \operatorname{lgSIZE}+0.041918 \operatorname{lgEBIT}$ (2013)

In 2013, with the company's operating conditions improved, the company is more inclined to narrow the financial leverage. 


\section{$\mathrm{LEV}=0.043514-0.000159 \mathrm{AGE}+0.026264 \mathrm{RATE}-$ $0.009779 \operatorname{lgSIZE}+0.008335 \operatorname{lgEBIT}(2014)$}

In 2014, as the company's operating conditions improved, the company was more inclined to expand its financial leverage.

As for the special 2014, we added the dummy variable 2014, taking 2014 as the node, after 2014, dummy variable is 1 , otherwise 0 , using model (5).

We get the result as followed:

ROA $=-0.7872-0.0016 \mathrm{AGE}-$

$0.02629 \mathrm{LEV}+0.173785 \operatorname{lgSIZE}+0.139831 \operatorname{lgEBIT}-$

$0.06899 \mathrm{ZERO}$

The results show that the dummy variable in 2014 has a negative impact on the company's operating conditions, that is, with the anti-corruption to promote the company's operating conditions are poor. However, according to the test results, this result is not significant $(\mathrm{p}=0.3687)$.

For the companies with different sizes, we re-analyze them with model (2), and we get results as followed:

$\mathrm{ROA}=-0.292059+0.0000461 \mathrm{AGE}-$

$0.13901 \mathrm{LEV}+0.093294 \operatorname{lgSIZE}+0.073774 \operatorname{lgEBIT}$ (large)

$\mathrm{ROA}=-5.983256-$

$0.00175 \mathrm{AGE}+0.00165 \mathrm{LEV}+0.430694 \mathrm{gSIZE}+0.1601 \mathrm{gEBIT}$

(small and medium)

From the results we can see that for large-scale enterprises, its leverage for the company's operating performance is negative; small and medium-sized enterprises is the opposite result. This result is consistent with our previous questions, at least from the results point of view is consistent. Indicating that the size of the enterprise, may be the demand for financial leverage is not so strong, and this may be with the situation of "too big to fail" is also consistent.

\section{CONCLUSIONS}

\section{A. The Overall Level of Financial Leverage}

The EBIT rate of the 3 years shows a gradual decline in the trend. Net assets yield from 0.0714 in 2012 to 0.0667 in 2013 , and then to 0.0687 , although there is a trend of reducing, 2013 is not much lower than in 2014, so the overall point of view is that the return on net assets also has a downward trend.

In the three years, the rise of the financial leverage of Chinese enterprises is not necessarily the initiative of enterprises, there may be passive, irrational reasons.

\section{B. Regressions}

The impact of corporate financial leverage on the performance of the firm is uncertain. In different situations, such as different corporate scales, different periods, different market conditions, the impact is not the same. In 2012, the impact of financial leverage on the performance of the company's operations was negative, which means that in that case, the company's higher financial leverage, the company's operating performance will be poor. In 2013, financial leverage for the company operating performance The impact is negative, which means that in this case, the company's financial leverage is higher, the company's operating performance will be poor. But in 2014, this situation has reversed, the financial leverage for the company's operating performance The effect is positive, which means that in this case, the company's higher financial leverage, the company's operating performance will be better.

Worth to mention, it may be a very critical year for China's enterprises may be a very critical year. China's government in 2014 gradually increased the intensity of anticorruption, to promote frugality, and China's economy in 2014 announced a new normal economic. China's economy into the new normal is an active choice, is a strategic adjustment, or a passive acceptance, these are still worthy of our continued mining, but at least from our analysis of the results point of view, 2014 is a different Of the year. The results of the reanalysis after the addition of the dummy variable also show that the 2014 variable for this period has an impact on the company's operating performance, but the credibility is not particularly significant.

\section{Companies of Different Scales}

For large-scale enterprises, its leverage for the company's operating performance is negative; small and medium-sized enterprises is the opposite result. This result is consistent with our previous questions, at least from the results point of view is consistent. Indicating that the size of the enterprise, may be the demand for financial leverage is not so strong, and this may be with the situation of "too big to fail" is also consistent.

\section{RECOMMENDATIONS}

Here are some recommendations for China's listed companies:

1. Different companies determine their own flexible financial leverage according to their own situation.

2. Seek a balance between financial flexibility and leverage.

3. Improve financial leverage flexibility.

4. Consider the cash flow of the enterprises seriously.

5. Establish a suitable risk control mechanism.

\section{REFERENCES}

[1] Crossman.S and 0.Hart.Corporate financial structure and managerial incentives[J].The Economical of Information and Uncertainty, 1982:107-140.

[2] Sandberg.S The Effect of Capital Structure on a Firm's Liquidation Decision[J].Journal of Financial Economicis, 1988(13):137-151.

[3] Rajan.R, H.Servaes and L.Zingales. The Cost of Diversity: The diversification Discount and Inefficient Investment[J]. Journal of Finance, 2003 (3): 77-80.

[4] Dudley, Evan, Christopher, James, Capital-structure Changes Around IPOs, Working Paper, University of Florida, 2013.

[5] Mark J. Flannery, Kasturi P. Rangan Partial adjustment toward target capital structures, Journal of Financial Economics, 2006(79):469-506.

[6] Li,M. and Y.Wong. Diversification and Economic Performance: An Empirical Assessment of Chinese Firms[J].Asia Pacific Journal of Management, 2003 (5): 243-259.

[7] S. Attaoui, P. Poncet Capital structure and debt priority, Financial Management, 2013 (42):737-775.

[8] Chaiporn Vithessonthi and Jittima Tongurai. The Effect of Firm Size on The Leverage-Performance Relationship During The 
Financial Crisis of 2007-2009[J]. Journal of Multinational Financial Management, 2015(29):1-29.

[9] J. Aizenman, M.D. Chinn, H. Ito. The emerging global financial architecture: tracing and evaluating new patterns of the trilemma configuration, J. Int. Money Financ., 2010(29): 615-641.
[10] D.J. Cumming, U. Walz Private equity returns and disclosure around the world, Journal of International Business Studies, 2010(41):727754 . 